ORIGINAL ARTICLE

\title{
Quality effects of operative delay on mortality in hip fracture treatment
}

\section{R Sund, A Liski}

Qual Saf Health Care 2005;14:371-377. doi: 10.1136/qshc.2004.012831

See end of article for authors' affiliations

....................

Correspondence to: R Sund, STAKES, $P$ O Box 220, FIN-00531 Helsinki, Finland; reijo.sund@ stakes.fi

Accepted for publication 7 August 2005
Background: Most hip fracture patients undergo surgery, but there is conflicting evidence on the relation between the timing of surgery and the outcome of treatment. There is considerable variation in the length of surgical delays between hospitals, possibly reflecting the quality of care.

Aim: To examine the associations between in-hospital surgical delay and the mortality of hip fracture patients from a practical quality assessment perspective.

Methods: The effects of operative delay on mortality were estimated using various statistical methods applied to observational data from 16881 first time hip fracture patients aged 65 or older from 47 hospitals (providers) in Finland in 1998-2001.

Results: A prolonged in-hospital operative delay was associated with a higher mortality of hip fracture patients in individual level analyses, but the instrumental variable approach indicated that the individual level effect was not caused by the operative delay but by inappropriate methodological assumptions. There was extensive variation between providers in the proportion of late surgery patients. Provider level analyses showed that the effects of the provider of operative delay on mortality are quite small, but there is a clear association between the proportion of late surgery patients and non-optimal treatment.

Conclusions: If provider level heterogeneity is not explicitly taken into account, studies of the effects of surgical delay on outcomes are prone to serious bias. The proportion of patients with prolonged waiting time for surgery at the provider level seems to work as an effective evidence-based quality indicator. Providers should reduce unnecessary delays to surgery and identify more carefully patients not suitable for early surgery.
$\mathrm{H}$ ip fractures are common injuries among older people and are associated with substantial morbidity and mortality. ${ }^{1-3}$ Ageing of the population has resulted in an increase in the mean age of hip fracture patients which is likely to cause additional problems in the treatment and rehabilitation of patients in the future. ${ }^{45}$ A surgical operation is performed for most patients during the acute management of hip fracture. A typical hip fracture patient is confined to hospital bed rest before surgery. A fairly short operative delay is suggested in the clinical guidelines, ${ }^{6-10}$ but it is known that there is considerable variation in the operative delays between providers. ${ }^{11-17}$ In fact, operative delay is a commonly used process measure in health system performance assessment. ${ }^{18}$ Minimisation of unnecessary preoperative inpatient care can be used as an economic justification for shorter operative delays. For quality measurement purposes, the operative delay should also have confirmed effects on outcomes otherwise improvements may possibly be targeted to issues which do not improve health. ${ }^{19}$ The evidence concerning the optimal timing of surgery in relation to the overall outcomes of hip fracture treatment is quite mixed. ${ }^{20-29}$ In short, the main reasons for variations in the operative delay are provider level system factors (availability of required resources such as operating rooms, support services, or personnel with expertise) and clinical decisions based on patient specific factors (co-morbidity, medical stabilisation). In some studies conflicting results may be due to methodological shortcomings (small numbers of observations, no adjustment for confounding factors), but more sophisticated evidence as to whether operative delay has an independent effect on primary outcomes is also conflicting. ${ }^{30-38}$ Another open question is the definition of the time period for delayed surgery. ${ }^{18}$ The impact of provider level heterogeneity on the effects of operative delay on outcomes has also not received sufficient attention.

This study was undertaken to examine the associations between the in-hospital operative delay and the mortality of hip fracture patients in Finland in 1998-2001. Since previous studies concerning the effect of operative delay on mortality had reported conflicting results, special attention was paid to methodological issues. More specific goals for empirical analyses were (1) to identify a suitable definition for early and late surgery groups, (2) to describe the postoperative excess mortality associated with prolonged operative delay, (3) to illustrate in which respect the early and late surgery groups differ from each other and whether adjustment of these observed factors changes the association between operative delay and mortality, (4) to compare the risk adjusted proportion of late surgery patients between providers, and (5) to investigate provider level heterogeneity in terms of 1 year mortality and the proportion of patients with late surgery.

\section{METHODS \\ Data set}

The total population of hip fracture patients in 1998-2001 was identified in the Finnish Health Care Register. The medical histories (1987-2002) and deaths (1998-2002) of the hip fracture population were extracted from the Finnish Hospital Discharge Register, Finnish Health Care Register, and from the National Causes of Death Register using the unique personal identification numbers of the patient population. Each record in these registers includes data such as patient and provider ID numbers, age, sex, area codes, and diagnosis and operation codes, as well as dates of admission, 
operation, and discharge (or death). The completeness and accuracy of the registers is known to be good. ${ }^{39-41}$

\section{Data preprocessing}

Data were preprocessed so that information concerning patients aged 65 or older with a first hip fracture could be accurately identified. ${ }^{42}$ For the purposes of this study, the data were restricted to patients operated on using an internal fixation, a prosthesis, or a total hip replacement. Patients with incomplete data were excluded from the analyses. A few providers (hospitals) had not reported operation dates for the years 1998-1999, but otherwise no systematic bias was found in the sensitivity analyses. The final study population consisted of 16881 patients, which represents $83.3 \%$ of all first time hip fracture patients aged 65 or older. Forty six providers had at least 50 cases, while the remaining 154 cases from other providers were combined into a single figure. The existence of possible co-morbidities was extracted for each patient from his or her medical history using the diagnosis codes recorded in the data. ${ }^{34} 43$ The extraction method was adapted and updated from the original Charlson co-morbidity categories ${ }^{44}$ and applied to the current data set.

\section{Statistical analyses}

Cumulative probabilities of unadjusted mortality were calculated using the product limit estimators. Excess risk of death was defined as difference in cumulative probabilities of mortality between two comparable groups. Hazard ratios were obtained using the proportional hazards model allowing the adjustment of observed confounders. Since only a limited number of covariates were observed, the biasing influence of unobserved heterogeneity was statistically controlled by incorporating the gamma frailty term into the model. ${ }^{45}$

The significance of the differences between the unadjusted patient characteristics was determined using the $\mathrm{z}$ test (binary variables) or $\chi^{2}$ test (categorical variables). The logistic regression model was used to calculate odds ratios and significances of differences between adjusted patient characteristics. The same logistic model was also used for predicting the late surgery probability for each patient. These probabilities were then aggregated to the provider level, resulting in the expected number of late surgery patients for each provider. ${ }^{46}$ The provider specific ratios between observed and expected numbers of late surgery patients were further modelled using the hierarchical gamma-Poisson model to obtain the comparable risk adjusted proportions of late surgery patients for providers. ${ }^{47}$ The weekday adjusted proportion was calculated using the predictive margin technique. ${ }^{48}$ In the instrumental variables analysis ${ }^{49}$ the 1 year adjusted mortality was calculated for each admission day of the week and the null hypothesis of equal mortalities was tested using the $\chi^{2}$ goodness of fit test. ${ }^{30}$

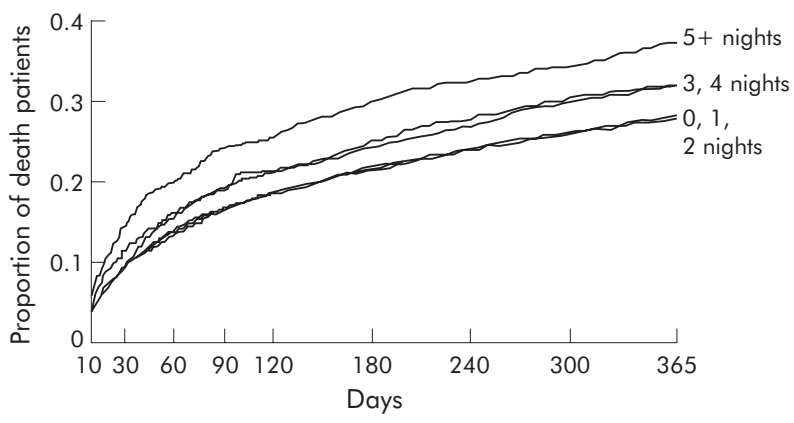

Figure 1 Cumulative probabilities of unadjusted mortality following hip fracture for operative delays of various lengths.

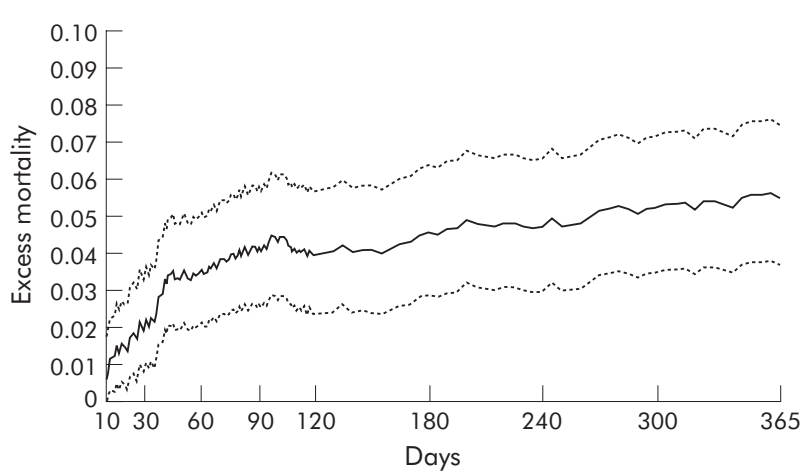

Figure 2 Unadjusted excess risk of death (with 95\% confidence interval) for late hip fracture surgery.

Provider level heterogeneity was examined in terms of the proportion of late surgery patients and 1 year mortality. The provider specific overall mortality rates were stratified according to early and late surgery, recognising the fact that the weighted average of these mortalities gives the overall mortality. The provider level associations between these three mortality rates and the proportions of late surgery patients were estimated using Stein estimation with an assumption of linear trends for overall and early surgery mortality rates. ${ }^{50}$ The associations were also analysed separately according to severity. The five severity groups were established by classifying the patients into five equal sized groups in terms of their predicted l year mortality based on the logistic regression model..$^{51}$

\section{RESULTS}

\section{Effect of length of operative delay on mortality}

The cumulative probabilities of unadjusted mortality rates attributable to different lengths of operative delay are shown in fig 1 . Waiting times of $0-2$ nights had the same effect on mortality, but there was a significant increase in mortality with waiting times of $3-4$ nights $(p<0.001)$, and waiting times of 5 or more nights resulted in an even higher mortality rate. Early surgery was defined as a waiting time of $0-2$ nights ( $\mathrm{n}=14426,85.5 \%)$ and late surgery as a waiting time of at least 3 nights $(\mathrm{n}=2455,14.5 \%)$. The unadjusted hazard ratio between late and early surgery was $1.24 \quad(95 \%$ confidence interval (CI) 1.15 to $1.34, \mathrm{p}<0.0001)$.

\section{Excess risk of death}

The unadjusted excess risk of death for late surgery compared with early surgery quickly rose to $3 \%$, then slowly increased during follow up to about $5 \%$ at 1 year (fig 2). Complementary analyses revealed that the excess risk was quite stable and near to its maximum at $1-3$ years and then began to decrease slowly. As the lower confidence limits in fig 2 indicate, the unadjusted excess risk of death became statistically significant 2 weeks after the operation.

\section{Characteristics of early and late surgery groups}

Characteristics of the patients with hip fracture classified into early and late surgery groups are shown in table 1, together with the corresponding odds ratios for late surgery adjusted for the other characteristics in the table. Early surgery was associated with being 85 years or older, of female sex, having a pertrochanteric fracture, and receiving long term inpatient care during the year preceding the admission. Admission on a Wednesday and a medical history of dementia or cataract were also associated with early surgery. The risks for late surgery were likely to be increased by admission from a nursing home, health centre or readmission shortly after 
Table 1 Characteristics of patients with hip fracture

\begin{tabular}{|c|c|c|c|c|c|c|}
\hline Characteristic & $\begin{array}{l}\text { Early surgery } \\
(n=14426,85.5 \%)\end{array}$ & $\begin{array}{l}\text { Late surgery } \\
\text { ( } n=2455,14.5 \%)\end{array}$ & $\begin{array}{l}\text { Unadjusted } \\
\text { p value }\end{array}$ & Odds ratio & $95 \% \mathrm{Cl}$ & $\begin{array}{l}\text { Adjusted } \\
\mathrm{p} \text { value }\end{array}$ \\
\hline $\begin{array}{l}\text { Age (years) } \\
65-74 \\
75-79 \\
80-84 \\
85-89 \\
90+\end{array}$ & $\begin{array}{l}2721(18.9) \\
2995(20.8) \\
3483(24.1) \\
3379(23.4) \\
1848(12.8)\end{array}$ & $\begin{array}{l}504(20.5) \\
491(20.0) \\
616(25.1) \\
556(22.6) \\
288(11.7)\end{array}$ & $<0.001$ & $\begin{array}{l}1 \\
0.885 \\
0.954 \\
0.867 \\
0.836\end{array}$ & $\begin{array}{l}0.770 \text { to } 1.017 \\
0.833 \text { to } 1.092 \\
0.753 \text { to } 0.998 \\
0.706 \text { to } 0.989\end{array}$ & $\begin{aligned} & 0.13 \\
& 0.086 \\
& 0.494 \\
< & 0.05 \\
< & 0.05\end{aligned}$ \\
\hline $\begin{array}{l}\text { Sex } \\
\text { Male } \\
\text { Female }\end{array}$ & $\begin{array}{r}3443(23.9) \\
10983(76.1)\end{array}$ & $\begin{array}{r}696(28.4) \\
1759(71.6)\end{array}$ & $<0.001$ & $\begin{array}{l}1 \\
0.844\end{array}$ & 0.762 to 0.935 & $\begin{array}{l}<0.01 \\
<0.01\end{array}$ \\
\hline $\begin{array}{l}\text { Fracture type } \\
\text { Pertrochanteric } \\
\text { Subtrochanteric } \\
\text { Femoral neck }\end{array}$ & $\begin{array}{r}4529(31.4) \\
835(5.8) \\
9065(62.8)\end{array}$ & $\begin{array}{r}694(28.3) \\
165(6.7) \\
1596(65.0)\end{array}$ & $<0.001$ & $\begin{array}{l}1 \\
1.241 \\
1.135\end{array}$ & $\begin{array}{l}1.027 \text { to } 1.500 \\
1.029 \text { to } 1.253\end{array}$ & $\begin{array}{l}<0.05 \\
<0.05 \\
<0.05\end{array}$ \\
\hline $\begin{array}{l}\text { Medical history } \\
\text { Cancer } \\
\text { Diabetes } \\
\text { Dementia } \\
\text { Hypertension } \\
\text { Cardiovascular disease } \\
\text { Cerebrovascular disease } \\
\text { Peripheral vascular disease } \\
\text { Chronic pulmonary disease } \\
\text { Anaemia } \\
\text { Diseases of the nervous system } \\
\text { Eye diseases† } \\
\text { Diseases of the digestive system } \ddagger \\
\text { Other diseases } \S\end{array}$ & $\begin{array}{r}1676(11.6) \\
1470(10.2) \\
2761(19.1) \\
2188(15.2) \\
5110(35.4) \\
2807(19.5) \\
632(4.4) \\
1205(8.4) \\
1161(8.0) \\
852(5.9) \\
4182(29.0) \\
2316(16.1) \\
2429(16.8)\end{array}$ & $\begin{array}{r}299(12.2) \\
290(11.8) \\
411(16.7) \\
444(18.1) \\
1108(45.1) \\
562(22.9) \\
174(7.1) \\
265(10.8) \\
236(9.6) \\
139(5.7) \\
673(27.4) \\
396(16.1) \\
432(17.6)\end{array}$ & $\begin{aligned} & 0.223 \\
&< 0.01 \\
&< 0.01 \\
&< 0.001 \\
&< 0.001 \\
&< 0.001 \\
&<0.001 \\
&<0.001 \\
&<0.01 \\
& 0.333 \\
& 0.058 \\
& 0.474 \\
& 0.185\end{aligned}$ & $\begin{array}{l}1.006 \\
1.006 \\
0.863 \\
1.104 \\
1.462 \\
1.110 \\
1.447 \\
1.148 \\
1.135 \\
0.895 \\
0.903 \\
0.940 \\
0.986\end{array}$ & $\begin{array}{l}0.878 \text { to } 1.151 \\
0.873 \text { to } 1.160 \\
0.762 \text { to } 0.976 \\
0.979 \text { to } 1.244 \\
1.329 \text { to } 1.609 \\
0.995 \text { to } 1.238 \\
1.207 \text { to } 1.736 \\
0.991 \text { to } 1.330 \\
0.972 \text { to } 1.319 \\
0.740 \text { to } 1.084 \\
0.816 \text { to } 1.000 \\
0.833 \text { to } 1.060 \\
0.877 \text { to } 1.108\end{array}$ & $\begin{array}{c}0.935 \\
0.931 \\
<0.05 \\
0.106 \\
<0.001 \\
0.062 \\
<0.001 \\
0.066 \\
0.109 \\
0.257 \\
<0.05 \\
0.310 \\
0.814\end{array}$ \\
\hline $\begin{array}{l}\text { Pre-admission residence } \\
\text { Home (>1 week) } \\
\text { Home (max } 1 \text { week) } \\
\text { Nursing home } \\
\text { Health centre } \\
\text { Hospital }\end{array}$ & $\begin{array}{r}9444(65.5) \\
685(4.7) \\
2508(17.4) \\
1249(8.7) \\
540(3.7)\end{array}$ & $\begin{array}{r}1559(63.5) \\
153(6.2) \\
416(16.9) \\
143(9.9) \\
84(3.4)\end{array}$ & $<0.001$ & $\begin{array}{l}1 \\
1.300 \\
1.215 \\
1.177 \\
0.888\end{array}$ & $\begin{array}{l}1.076 \text { to } 1.570 \\
1.016 \text { to } 1.451 \\
1.000 \text { to } 1.384 \\
0.694 \text { to } 1.135\end{array}$ & $\begin{array}{c}<0.01 \\
<0.05 \\
<0.05 \\
0.341\end{array}$ \\
\hline $\begin{array}{l}>180 \text { days inpatient care during year } \\
\text { preceding fracture }\end{array}$ & $2569(17.8)$ & 402 (16.4) & $<0.05$ & 0.823 & 0.691 to 0.979 & $<0.05$ \\
\hline $\begin{array}{l}\text { Day of admission } \\
\text { Monday } \\
\text { Tuesday } \\
\text { Wednesday } \\
\text { Thursday } \\
\text { Friday } \\
\text { Saturday } \\
\text { Sunday }\end{array}$ & $\begin{array}{l}2479(17.2) \\
2289(15.9) \\
2248(15.6) \\
2091(14.5) \\
1898(13.2) \\
1744(12.1) \\
1677(11.6)\end{array}$ & $\begin{array}{r}307(12.5) \\
288(11.7) \\
220(9.0) \\
401(16.3) \\
678(27.6) \\
358(14.6) \\
203(8.3)\end{array}$ & $<0.001$ & $\begin{array}{l}1 \\
1.026 \\
0.803 \\
1.567 \\
2.970 \\
1.686 \\
0.989\end{array}$ & $\begin{array}{l}0.864 \text { to } 1.218 \\
0.668 \text { to } 0.964 \\
1.334 \text { to } 1.840 \\
2.559 \text { to } 3.447 \\
1.429 \text { to } 1.990 \\
0.818 \text { to } 1.195\end{array}$ & $\begin{aligned} &< 0.001 \\
& 0.770 \\
&<0.05 \\
&<0.001 \\
&<0.001 \\
&<0.001 \\
& 0.907\end{aligned}$ \\
\hline $\begin{array}{r}\text { Year** }^{* *} \\
1998 \\
1999 \\
2000 \\
2001\end{array}$ & $\begin{array}{l}3275(83.1) \\
3325(84.8) \\
3869(86.1) \\
3957(87.5)\end{array}$ & $\begin{array}{l}667(16.9) \\
597(15.2) \\
625(13.9) \\
566(12.5)\end{array}$ & $<0.001$ & $\begin{array}{l}1 \\
0.877 \\
0.801 \\
0.700\end{array}$ & $\begin{array}{l}0.775 \text { to } 0.992 \\
0.709 \text { to } 0.904 \\
0.619 \text { to } 0.793\end{array}$ & $\begin{array}{l}<0.001 \\
<0.05 \\
<0.001 \\
<0.001\end{array}$ \\
\hline
\end{tabular}

*Includes Parkinson's disease, hemiplegia or paraplegia, and epilepsy.

†Includes glaucoma and cataract.

flncludes peptic ulcer disease, abdominal hernia, liver disease, disorders of gallbladder and biliary tract, and irritable colon.

§lncludes hypothyroidism, gout, renal disease, arthrosis, and rheumatic disease.

- Health centre refers to the inpatient ward of the local primary health care unit

**Percentages in parentheses are the proportions of the categories in the current year.

discharge, admission between Thursday and Saturday, and co-morbidities including cardiovascular disease and peripheral vascular disease (and, prior to adjustment, diabetes, cerebrovascular disease, chronic pulmonary disease, hypertension, and anaemia). The proportion of patients having late surgery substantially decreased during the period of the study.

\section{Adjusted effect of operative delay on mortality}

The hazard ratio for the late surgery reduced to 1.18 (95\% CI 1.09 to $1.28, \mathrm{p}<0.0001$ ) after adjusting for the provider and the characteristics in table 1. Even after controlling for the unobserved covariates, the hazard ratio remained significant, indicating an increased mortality for late surgery. However, after the pseudo randomised assignment of patients into early and late surgery groups using admission day of the week as an instrumental variable, the difference in the adjusted 1 year mortality rate was found not to be attributable to operative delay $(\mathrm{p}=0.069)$.

\section{Proportions of late surgery patients}

There was extensive variation in the proportions of late surgery patients between providers (fig 3). The conservative $95 \%$ confidence interval crosses the potentially achievable 


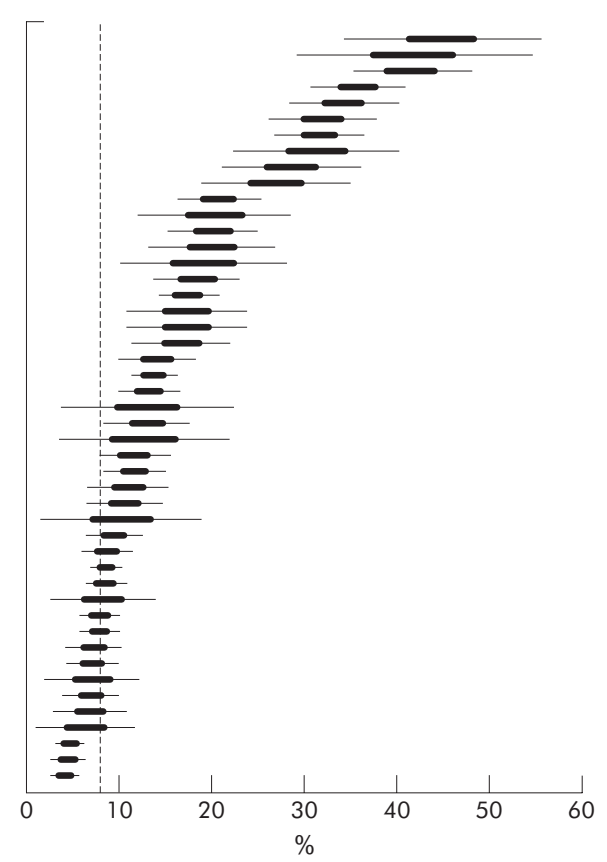

Figure 3 Provider-specific risk adjusted percentages of hip fracture patients undergoing late surgery. The thin parts of the lines correspond to $95 \%$ confidence intervals and the thick parts correspond to $50 \%$ confidence intervals. The dashed line refers to the potentially achievable percentage $(7.7 \%)$ of patients undergoing late surgery.

(20th centile) $^{52} 92.3 \%$ share of patients undergoing early surgery for less than $50 \%$ of the providers.

\section{Trend analysis at provider level}

The simultaneous examination of the provider level proportions of late surgery patients and 1 year mortality rates showed that there was a statistically significant positive trend for an association between a larger share of late surgery patients and 1 year overall mortality $(\mathrm{p}<0.05)$, and that a smaller proportion of late surgery patients was (non-linearly) associated with a higher mortality rate for these patients (fig 4).

\section{Trend analyses for severity groups}

The associations were further analysed according to severity (measured as predicted 1 year mortality based on the same observed patient characteristics as in table 1) in five severity groups of patients (table 2). The proportion of patients undergoing late surgery was only slightly higher in the more severe patient groups but the 1 year mortality rate increased significantly with severity, as expected. The slope of the trend of overall mortality increased with the severity but was statistically significant only for the most severe patients. The positive slope of early surgery mortality was statistically significant in severity groups 3 and 4, but for the most severe patients this association disappeared. A smaller proportion of late surgery patients was associated with a higher late surgery mortality rate in all groups except the most severe patients.

\section{DISCUSSION}

In this study the definition of late surgery turned out to be 3 or more nights in hospital after admission, since shorter waiting times were not associated with higher unadjusted mortality. A similar "long" delay is commonly used as the definition of late surgery in other studies. ${ }^{17} 182034$

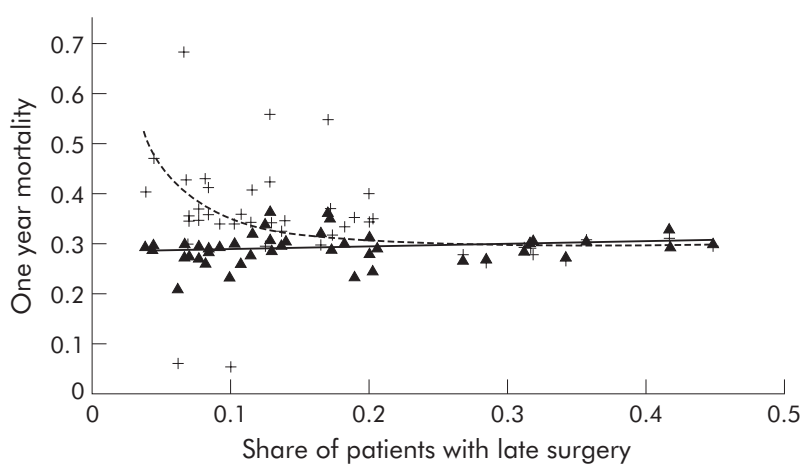

Figure 4 Scatter plot of adjusted mortality for surgically treated hip fracture patients and the share of patients undergoing late surgery for different providers (The triangles represent the overall mortality of operated hip fracture patients for each provider and the crosses the mortality of late surgery patients for each provider. The line with a positive slope is the trend of overall mortality and the dotted curved line indicates the association between the share of late surgery patients and late surgery mortality across providers).

The unadjusted excess mortality for late surgery patients increased during the year following the operation. It is interesting that the short term mortality differed only slightly between early and late surgery groups, but the difference became much clearer after the perioperative period. This may be partly due to the fact that almost half the perioperative deaths are unavoidable in an unselected population. ${ }^{53}$ If patients are going to die shortly after the fracture-regardless of the quality of the hip fracture treatment provided-it is obvious that the treatment effect turns out to be small. The treatment effect becomes observable for long term mortality but is potentially biased because of heterogeneity between the early and late surgery groups in patient characteristics affecting the outcome..$^{20} 303336$

Several patient characteristics differed between the early and late surgery groups, but the prolonged operative delay seemed to increase the (long term) mortality significantly even after adjustment for these observed patient characteristics. There were no detailed clinical data available which obviously makes the adjustments only partial. The bias attributable to the unobserved covariates was controlled by allowing extra variation in the model, but the treatment effect remained significant. However, this kind of model is still prone to bias if the relationships between the risk factors and mortality are not correctly specified in the model. ${ }^{54}$ The pseudo randomizing instrumental variable approach was therefore applied and indicated that the increased mortality was not due to operative delay. Since the interpretations based on the instrumental variable approach also require strong and questionable assumptions, ${ }^{30}{ }^{33}$ the sizeable difference in the estimates of the effect of operative delay on mortality between methods means that there is a need for hypotheses to explain such differences.

For instance, one could try to separate the acceptable delays from the unacceptable ones ${ }^{27}{ }^{36}$ or one could record the reason for the delay in the data. ${ }^{17} 3132$ In the strictest sense, this kind of approach needs the assumption that the acceptable and unacceptable delays can be defined and measured uniquely. ${ }^{55-57}$ In practice, an acceptable delay corresponds to a clinical decision to postpone the operation and the assumption is approximately fulfilled if the clinical practice remains constant. Because the data used in this study did not include the reason for the delay, the hypothesis of constant clinical practice was examined indirectly using provider level analyses. 
Table 2 Effect of proportion of late surgery patients on mortality in different severity groups of hip fracture patients

\begin{tabular}{|c|c|c|c|c|c|c|}
\hline & \multirow[b]{2}{*}{ n (\%) } & \multicolumn{4}{|l|}{ One year mortality } & \multirow[b]{2}{*}{$\begin{array}{l}\text { Slope }^{*} \\
\text { (p value) }\end{array}$} \\
\hline & & $\begin{array}{l}10 \% \text { of patients } \\
\text { with late surgery }\end{array}$ & $\begin{array}{l}15 \% \text { of patients } \\
\text { with late surgery }\end{array}$ & $\begin{array}{l}20 \% \text { of patients } \\
\text { with late surgery }\end{array}$ & $\begin{array}{l}30 \% \text { of patients } \\
\text { with late surgery }\end{array}$ & \\
\hline \multicolumn{7}{|c|}{ All patients (adjusted mortality)† } \\
\hline Overall & 16881 & 29.0 & 29.3 & 29.5 & 30.0 & $0.5(<0.05)$ \\
\hline Early surgery & $14426(85)$ & 28.4 & 28.8 & 29.3 & 30.2 & $0.9(<0.01)$ \\
\hline Late surgery & $2455(15)$ & $35.0 \ddagger$ & 31.9 & 30.5 & 29.7 & \\
\hline \multicolumn{7}{|c|}{ Patient group 1 (least severe) } \\
\hline Overall & $3376(20)$ & 9.4 & 9.3 & 9.2 & 9.0 & $-0.2(0.232)$ \\
\hline Early surgery & $2931(87)$ & 8.8 & 8.6 & 8.4 & 8.1 & $-0.3(0.168)$ \\
\hline Late surgery & 445 (13) & 15.4 & 13.4 & 12.4 & 11.1 & \\
\hline \multicolumn{7}{|l|}{ Patient group 2} \\
\hline Overall & $3376(20)$ & 18.0 & 17.9 & 17.8 & 17.6 & $-0.2(0.283)$ \\
\hline Early surgery & $2932(87)$ & 17.4 & 17.5 & 17.7 & 17.9 & $0.2(0.310)$ \\
\hline Late surgery & $444(13)$ & 23.8 & 20.1 & 18.4 & 16.7 & \\
\hline \multicolumn{7}{|l|}{ Patient group 3} \\
\hline Overall & $3376(20)$ & 26.9 & 27.2 & 27.6 & 28.2 & $0.6(0.101)$ \\
\hline Early surgery & $2875(85)$ & 26.6 & 27.5 & 28.5 & 30.4 & $1.9(<0.01)$ \\
\hline Late surgery & 501 (15) & 29.7 & 25.4 & 23.8 & 23.1 & \\
\hline \multicolumn{7}{|l|}{ Patient group 4} \\
\hline Overall & $3377(20)$ & 37.9 & 38.3 & 38.7 & 39.5 & $0.8(0.126)$ \\
\hline Early surgery & $2869(85)$ & 37.4 & 38.3 & 39.2 & 41.1 & $1.8(<0.05)$ \\
\hline Late surgery & $508(15)$ & 43.0 & 38.5 & 36.7 & 35.8 & \\
\hline \multicolumn{7}{|c|}{ Patient group 5 (most severe) } \\
\hline Overall & $3376(20)$ & 51.4 & 51.9 & 52.5 & 53.5 & $1.1(<0.05)$ \\
\hline Early surgery & 2819 (84) & 50.7 & 50.6 & 50.6 & 50.5 & $-0.1(0.455)$ \\
\hline Late surgery & $557(16)$ & 57.9 & 59.3 & 59.9 & 60.6 & \\
\hline \multicolumn{7}{|c|}{ 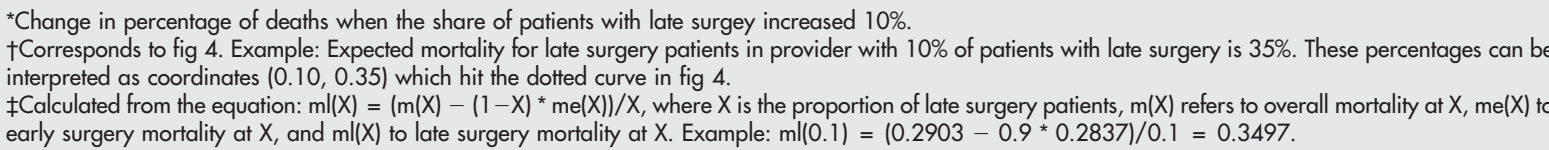 } \\
\hline
\end{tabular}

The provider specific proportion of late surgery patients, adjusted for observed patient characteristics, showed that there was extensive variation between providers, which is a common finding. ${ }^{11-17}$ A simple performance assessment interpretation is that the percentage of late surgery patients can be reduced to a potentially achievable level ${ }^{52}$ that can also be interpreted as the upper limit for the proportion of acceptable delayed patients. Correspondingly, the expected proportion of unacceptable delayed patients is the proportion of late surgery patients exceeding this upper limit. This leads to the hypothesis that the overall mortality of hip fracture patients should increase with an increasing proportion of late surgery patients given that the longer operative delay would have an adverse effect on mortality. In fact, a statistically significant trend between the provider specific proportions of late surgery patients and overall 1 year mortality gives empirical evidence for the hypothesis, but the actual volume of the effect was small. Another provider level hypothesis is that the long term mortality of late surgery patients is higher if only the patients unfit for surgery are delayed, since the unfit condition for surgery is also a risk factor for 1 year mortality. This hypothesis was also supported by empirical evidence which revealed a non-linear association between the provider specific proportion of late surgery patients and the 1 year mortality rate for these patients.

A more careful examination of the groups of patients with different predicted mortality (severity) gave even more insight into the provider level association between the proportion of late surgery patients and mortality. Intuitively speaking, the least severe patients are young, come from home, and are without severe medical conditions. Correspondingly, the most severe patients are older with much co-morbidity and come from residential care. ${ }^{2131}{ }^{53}$ For patients in the least severe group, mortality was higher in the late surgery patients for all providers. This probably indicates that, in this group, hip fracture related mortality is caused by the medical problems which require late surgery and the prolonged surgical delay does not itself increase the mortality..$^{28} 303136$ For patients in the most severe group mortality was also higher for the late surgery patients for all providers. However, in this group the mortality rate in the late surgery patients was lower in the providers with a small proportion of late surgery patients and there were no differences in mortality rates among early surgery patients between providers. This means that, in this group, it is essential to perform early surgery in all patients who can withstand it because the significantly prolonged surgical delay makes the patient's condition worse and increases mortality. ${ }^{22} 23293233$ For groups 2-4 the interpretation is more difficult than for patients in the extreme groups. Since the mortality rate in early surgery patients increases significantly and is higher even than the mortality rate of late surgery patients for providers with a large proportion of late surgery patients, it seems that in these groups an operation performed too early may cause more harm than the prolonged waiting time..$^{2122} 26$

Other differences between providers in the proportion of patients with late surgery result mainly from lack of resources such as temporary unavailability of the operating rooms or surgeons and problems with obtaining medical clearance from other specialities in off hours. ${ }^{5758}$ The importance of these factors can be illustrated using the effect of the admission day on the in-hospital operation delay; the mean proportion of patients undergoing late surgery would be reduced from $14.5 \%$ to $9.0 \%(\mathrm{p}<0.0001)$ if all patients had been admitted on "the best day".

In spite of the large nationwide database and the advanced methods, the observational study design and administrative data require a special orientation to the analyses and caution should be exercised when interpreting the results. Data were available for 1998-2001 and the practices may have disproportionately changed for the different providers during 
that time. The results must therefore be interpreted as the mean situation between the years 1998-2001 for each provider. Non-operated patients were excluded from the analyses since the operative delay was not defined uniquely for these patients. Inclusion of these patients would certainly increase the mortality rate since the typical non-operated patient is in a worse condition and dies before any operation can even take place. The trend analyses are intended to summarise the systematic parts of the variation between the providers. However, there seems to be some unexplained variation, especially in the proportions of late surgery patients, because of the small number of patients for some providers, so the results of the trend analyses need to be confirmed and validated in further studies.

Study designs which explicitly take into account the heterogeneity at the provider level are a prerequisite for unbiased results since the selection bias may vary between providers. One could also include the provider level characteristics in the analyses, ${ }^{35}{ }^{37}$ but easily observable characteristics such as hospital type or number of surgeons typically allow only indirect interpretations. A more direct approach would be to observe the performance of providers continuously and to ask the providers themselves to clarify the reasons for their performance. ${ }^{12} 5859$

In Finland the mean proportion of late surgery patients has decreased during the years of the study, but extensive variation between providers exists. In addition to possible system problems, there also seems to be variation in the clinical practices for judging which patients are suitable for early surgery. Identification of good practices and the release of a national clinical guideline for hip fracture treatment will probably improve the situation. In this sense, the proportion of patients with a prolonged waiting time for a hip fracture operation seems to be an effective evidence based quality indicator, since it clearly indicates an area for improvement. The effects of operative delay on mortality at the patient level are quite small, but at the provider level the association between the proportion of late surgery patients and nonoptimal treatment is clear.

\section{Authors' affiliations}

R Sund, A Liski, National Research and Development Centre for Welfare and Health (STAKES), Outcomes and Equity Research, Helsinki, Finland

This research was supported by a research grant from the Academy of Finland.

\section{REFERENCES}

1 Zuckerman JD. Hip fracture. N Engl J Med 1996;334:1519-25.

2 Roberts SE, Goldacre MJ. Time trends and demography of mortality after fractured neck of femur in an English population, 1968-98: database study. BMJ 2003;327:771-5

3 Liporace FA, Egol KA, Tejwani N, et al. What's new in hip fractures? Current concepts. Am J Orthop 2005;34:66-74.

4 Marks R, Allegrante JP, Ronald MacKenzie C, et al. Hip fractures among the elderly: causes, consequences and control. Ageing Res Rev 2003;2:57-93.

5 Thorngren KG, Hommel A, Norrman PO, et al. Epidemiology of femoral neck fractures. Injury 2002;33:Cl-7.

6 Royal College of Physicians. Fractured neck of femur. Prevention and management. Summary and recommendations of a report of the Royal College of Physicians. J R Coll Physicians Lond 1989;23:8-12.

7 Chilov MN, Cameron ID, March LM. Evidence-based guidelines for fixing broken hips: an update. Med J Aust 2003;179:489-93.

8 Scottish Intercollegiate Guidelines Network. Prevention and management of hip fracture in older people. Edinburgh: Scottish Intercollegiate Guidelines Network, 2002

9 New Zealand Guidelines Group. Acute management and immediate rehabilitation after hip fracture amongst people aged 65 years and over. Wellington, NZ: New Zealand Guidelines Group, 2003.

10 Thorngren KG, Dolk T, Jarnlo GB, et al. National guidelines for care and treatment of hip fractures (in Swedish). Stockholm: The National Board of Health and Welfare, 2003

11 Audit Commission. United they stand, Co-ordinating care for elderly patients with hip fracture. London: Audit Commission, 2000.
12 Freeman C, Todd C, Camilleri-Ferrante C, et al. Quality improvement for patients with hip fracture: experience from a multi-site audit. Qual Saf Health Care 2002;11:239-45.

13 New Zealand Health Information Service (NZHIS). Fracture of neck of femur services in New Zealand hospitals 1999/2000. Wellington: New Zealand Health Information Service (NZHIS), 2002

14 Bottle A, Jarman B, Aylin P, et al. Some way to go for consistent implementation of guidance on hip fracture. BMJ 2004;328:1097.

15 Scottish Hip Fracture Audit Steering Group (SHFASG). Scottish hip fracture audit report 2002. Edinburgh: NHS Scotland, 2002.

16 Heikkinen T, Willig R, Hanninen A, et al. Hip fractures in Finland: a comparison of patient characteristics and outcomes in six hospitals. Scand J Surg 2004;93:234-40.

17 Todd CJ, Freeman CJ, Camilleri-Ferrante C, et al. Differences in mortality after fracture of hip: the East Anglian audit. BMJ 1995;310:904-8.

18 Fairbank J, Goldacre MJ, Mason A, et al. Health outcome indicators: fractured proximal femur, Report of a Working Group to the Department of Health. Oxford: National Centre for Health Outcomes Development, 1999.

19 Brook RH, McGlynn EA, Cleary PD. Quality of health care. Part 2: measuring quality of care. N Engl J Med 1996;335:966-70.

20 Zuckerman JD, Skovron ML, Koval KJ, et al. Postoperative complications and mortality associated with operative delay in older patients who have a fracture of the hip. J Bone Joint Surg Am 1995;77:1551-6.

21 Mullen JO, Mullen NL. Hip fracture mortality. A prospective, multifactorial study to predict and minimize death risk. Clin Orthop Relat Res 1992;280:214-22.

22 Kenzora JE, McCarthy RE, Lowell JD, et al. Hip fracture mortality. Relation to age, treatment, preoperative illness, time of surgery, and complications. Clin Orthop Relat Res 1984; 186:45-56.

23 Casaletto JA, Gatt R. Post-operative mortality related to waiting time for hip fracture surgery. Injury 2004;35:114-20.

24 McGoye PF, Evans J. Fractures of the hip: Immediate versus delayed treatment. Can Med Assoc J 1960;83:260-3.

25 Davis FM, Woolner DF, Frampton C, et al. Prospective, multi-centre trial of mortality following general or spinal anaesthesia for hip fracture surgery in the elderly. Br J Anaesth 1987;59:1080-8.

26 Kern IB. Fractures of the neck of the femur: a review of 308 cases treated at the Prince of Wales Hospital from January 1960 to June 1961. Med J Aust 1962:49:554-7.

27 Bredahl C, Nyholm B, Hindsholm KB, et al. Mortality after hip fracture: results of operation within $12 \mathrm{~h}$ of admission. Injury 1992;23:83-6.

28 Holt EM, Evans RA, Hindley CJ, et al. 1000 femoral neck fractures: the effect of pre-injury mobility and surgical experience on outcome. Injury 1994;25:91-5.

29 Hoenig $\mathbf{H}$, Rubenstein LV, Sloane R, et al. What is the role of timing in the surgical and rehabilitative care of community-dwelling older persons with acute hip fracture? Arch Intern Med 1997;157:513-20.

30 Ho V, Hamilton BH, Roos LL. Multiple approaches to assessing the effects of delays for hip fracture patients in the United States and Canada. Health Serv Res 2000;34:1499-518.

31 Grimes JP, Gregory PM, Noveck H, et al. The effects of time-to-surgery on mortality and morbidity in patients following hip fracture. Am J Med 2002; 1 12:702-9.

32 Moran CG, Wenn RT, Sikand M, et al. Early mortality after hip fracture: is delay before surgery important? J Bone Joint Surg Am 2005;87:483-9.

33 McGuire KJ, Bernstein J, Polsky D, et al. The 2004 Marshall Urist award: delays until surgery after hip fracture increases mortality. Clin Orthop Relat Res 2004;428:294-301.

34 Roos LL, Walld RK, Romano PS, et al. Short-term mortality after repair of hip fracture. Do Manitoba elderly do worse? Med Care 1996;34:310-26.

35 Weller I, Wai EK, Jaglal S, et al. The effect of hospital type and surgical delay on mortality after surgery for hip fracture. J Bone Joint Surg $\mathrm{Br}$ 2005;87:361-6.

36 Orosz GM, Magaziner J, Hannan EL, et al. Association of timing of surgery for hip fracture and patient outcomes. JAMA 2004;291:1738-43.

37 Hamilton BH, Hamilton VH, Mayo NE. What are the costs of queuing for hip fracture surgery in Canada? J Health Econ 1996;15:161-85.

38 Hamilton BH, Bramley-Harker RE. The impact of the NHS reforms on queves and surgical outcomes in England: Evidence from hip fracture patients. Econ $J$ 1999; 109:437-62.

39 Keskimäki I, Aro S. Accuracy of data on diagnoses, procedures and accidents in the Finnish Hospital Discharge Register. Int J Health Sci 1991;2:15-21.

40 Lahti RA, Penttila A. The validity of death certificates: routine validation of death certification and its effects on mortality statistics. Forensic Sci Int 2001;115:15-32.

41 Luthje P, Nurmi I, Kataja $M$, et al. Incidence of pelvic fractures in Finland in 1988. Acta Orthop Scand 1995;66:245-8.

42 Sund R. Utilisation of administrative registers using scientific knowledge discovery. Intelligent Data Analysis 2003;7:501-19.

43 Romano PS, Roos LL, Jollis JG. Adapting a clinical comorbidity index for use with ICD-9-CM administrative data: differing perspectives (with discussion). $J$ Clin Epidemiol 1993;46:1075-90.

44 Charlson ME, Pompei P, Ales KL, et al. A new method of classifying prognostic comorbidity in longitudinal studies: development and validation. J Chronic Dis 1987;40:373-83

45 Hougaard P. Frailty models for survival data. Lifetime Data Anal 1995; 1:255-73.

46 Goldstein H, Spiegelhalter DJ. League tables and their limitations: statistical issues in comparisons of institutional performance (with discussion). J R Sta Soc Ser A Stat Soc 1996;159:385-443. 
47 Howley PP, Gibberd R. Using hierarchical models to analyse clinical indicators: a comparison of the gamma-Poisson and beta-binomial models. Int J Qual Health Care 2003;15:319-29.

48 Graubard BI, Korn EL. Predictive margins with survey data. Biometrics 1999:55:652-9.

49 Newhouse JP, McClellan M. Econometrics in outcomes research: the use of instrumental variables. Annu Rev Public Health 1998;19:17-34.

50 Greenland S. Principles of multilevel modelling. Int J Epidemiol 2000;29:158-67.

51 Daley J, lezzoni LI, Shwartz M. Conceptual and practical issues in developing risk-adjustment methods. In: lezzoni LI, eds. Risk adjustment for measuring health care outcomes. 3rd edn. Chicago: Health Administration Press, 2003:179-205.

52 Gibberd R, Hancock S, Howley P, et al. Using indicators to quantify the potential to improve the quality of health care. Int J Qual Health Care 2004; 16:i37-43.

53 Foss NB, Kehlet $\mathrm{H}$. Mortality analysis in hip fracture patients: implications for design of future outcome trials. Br J Anaesth 2005;94:24-9.
54 Shwartz M, Ash AS. Estimating the effect of an intervention from observational data. In: lezzoni LI, eds. Risk adjustment for measuring health care outcomes. 3rd edn. Chicago: Health Administrative Press, 2003:275-95

55 Schultz RJ, Whitfield GF, LaMura JJ, et al. The role of physiologic monitoring in patients with fractures of the hip. J Trauma 1985;25:309-16.

56 Charalambous CP, Yarwood S, Paschalides C, et al. Factors delaying surgical treatment of hip fractures in elderly patients. Ann $R$ Coll Surg Engl 2003:85:117-9.

57 Orosz GM, Hannan EL, Magaziner J, et al. Hip fracture in the older patient: reasons for delay in hospitalization and timing of surgical repair. J Am Geriatr Soc 2002;50:1336-40.

58 Beupre LA, Johnston DB, Jones CA, et al. Continuum of care and integration of services for treatment of elderly patients with hip fracture. Alberta: Alberta Heritage Foundation for Medical Research (AHFMR), 2003.

59 Parker MJ, Currie CT, Mountain JA, et al. Standardised audit of hip fracture in Europe (SAHFE). Hip Int 1998;8:10-5. 